\title{
Temperature and humidity control system for broiler chicken coops
}

\author{
Ramadiani $^{1}$, Eko Wiji Setio Budianto ${ }^{2}$, Dharma Widada ${ }^{3}$, Masayu Widiastuti ${ }^{4}$, \\ Muhammad Labib Jundillah ${ }^{5}$ \\ 1,2,5 Department of Computer Science, Mulawarman University, Indonesia \\ ${ }^{3,4}$ Faculty of Engineering, Mulawarman University, Indonesia
}

\begin{tabular}{l} 
Article Info \\
\hline Article history: \\
Received Jan 13, 2021 \\
Revised Mar 4, 2021 \\
Accepted Mar 28, 2021 \\
\hline
\end{tabular}

Keywords:

Arduino

Broiler

Chicken coop

Humidity

Microcontroller

Temperatures

\section{Corresponding Author:}

Ramadiani

Department of Computer Science

Mulawarman University

Campus Kelua, Mulawarman University, Samarinda 75119, East Kalimantan, Indonesia

Email: ilkom.ramadiani@gmail.com

\begin{abstract}
Stress in chickens due to rising cage temperatures is a problem that is often faced by breeders, especially broiler breeders. Research with the title "temperature and humidity control system for broiler chicken coops", has formulated the research problem as follows; how to make an automatic control system to maintain the temperature and humidity of the ras broiler chicken coop to keep it stable using Arduino Uno ATMega328. In this tool it has been set, if the temperature is $\geq 30^{\circ} \mathrm{C}$ then the water pump will turn on, and the water pump will turn off when the temperature is $\leq 29^{\circ} \mathrm{C}$. Based on the results in this study, the temperature and humidity control system succeeded in helping farmers keep the temperature of the ras broiler chicken coop remained stable, so that farmers' production can be increased. In addition, this system also helps efficiency in terms of time and labor, because this system works automatically.
\end{abstract}

This is an open access article under the CC BY-SA license.

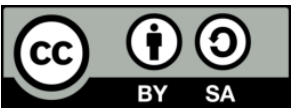

\section{INTRODUCTION}

The livestock industry in the tropics is confronted with high ambient temperatures, so the pace growth and production of eggs produced incompatible with animal genetic potential. Chicken livestock classified as warm-blooded animals (homeothermic) with specific characteristics do not have sweat glands and almost all parts of his body covered with fur. Hot conditions make it difficult for chickens to dispose of body heat into the environment [1]-[3]. As a result, broiler chickens raised in the tropics are vulnerable to the danger of heat stress. Stress is defined as a condition in an animal that results from the action of one or more stressors that may be of either external or internal origin. Heat stress can be defined as a condition in livestock that experiences an extreme temperature increase that comes from outside or from inside the room [1]-[6].

Lack of adequate facilities in dealing with stress in broilers is often a problem that is often faced by farmers to stabilize the humidity of the open cage room air. Some ways to stabilize the humidity of the cage air, one of them is by using a water pump that will be splashed to broiler chickens that have increased temperatures. This is considered effective, to increase the level of humidity in the cage, which is seen from the behavior of the animals themselves [4]-[11]. Then from that we need a microcontroller-based automatic control system as a tool for breeders to stabilize the humidity of the broiler chicken cage [11]-[23]. In this researcher has produced a tool to stabilize the humidity of the broiler chicken cage room by turning on and 
off the water pump automatically using a humidity sensor that is connected to the arduino microcontroller, and commands the water pump based on a standardized temperature that has been set. The microcontroller will provide instructions to turn off or turn on the water pump through a humidity sensor, where the sensor will read the temperature of the broiler chicken house coop then instruct arduino to turn on the switch, and turn on the water pump which will then automatically flow into the pipe to be poured on the broiler coop which has increased air humidity. Based on the explanation above, this research takes the title, "temperature and humidity control system for broiler chicken coops".

\section{RESEARCH METHOD}

\subsection{Mechanisms of heat production in broiler chickens}

Broilers are superior breeds of chickens through the crossing of various types of chicken that have high productivity, especially in the production of chicken meat [1]-[9]. Heat stress is a condition in which livestock experiences stress due to the heat produced by the body beyond its capacity to dispose of it into the environment. Heat stress often occurs in chickens when the ambient temperature is higher than the comfortable temperature of the chicken. The negative impact caused can threaten the sustainability of production and even the safety of chickens. Not a few farmers who experience losses due to mortality (death) are very high when the chickens are exposed to heat stress. Chickens do not have sweat glands, so the heat produced by the body due to metabolic processes cannot be released optimally when the ambient temperature is high. When chickens are stressed, the body will respond to reduce discomfort due to heat stress. Some of the responses shown were reduced chicken activity. Chickens will tend to be quiet a lot and decrease appetite, avoid contact with other chickens, reduce feed consumption, increase water consumption and do panting (breathing quickly) [6]-[13]. Chicken body temperature must be maintained around $39.9-41{ }^{\circ} \mathrm{C}$, the chicken will die if the body temperature rises by $41{ }^{\circ} \mathrm{C}$ or more as shown in Figure 1 . Broilers have fast growth and a fast metabolism rate, accompanied by high heat production due to high feed consumption. Chickens are homeothermic that maintain body temperature in a narrow range, the ability to anticipate heat decreases when the ambient temperature rises as shown in Figure 2.

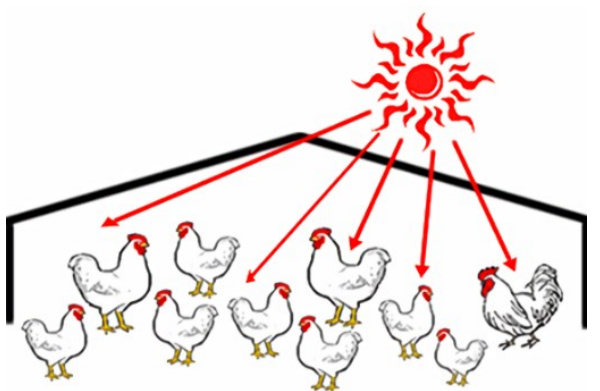

Figure 1. Heat stress in poultry

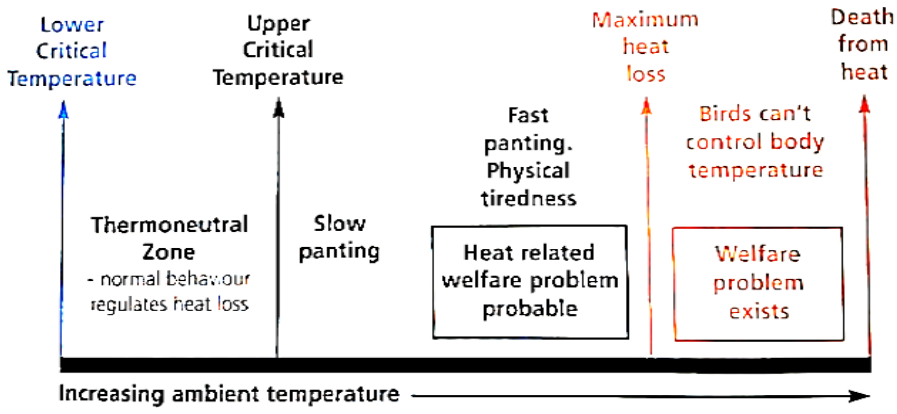

Figure 2. Diagram of thermoneutral zone [5]

\subsection{Microcontroller}

Microcontroller is an integrated circuit (IC) which contains central processing unit (CPU), read only memory (ROM), random access memory (RAM), and input/output (I/O). With this CPU, the microcontroller can do the thinking process based on the command program that has been given to it. Microcontroller can also be called a small-sized computer that is low-power so that a battery can provide power [13]-[25]. Arduino is the most popular microcontroller in the world because it is open source, developers are everywhere, and it's easy to find references. In Arduino Uno there is already an ATMega328 microcontroller, which has 14 digital input/output pins; the Arduino circuit is also equipped with a regulator IC that functions as a power supply circuit. The ATmega 328 microcontroller separates memory for program code and memory for data so that it can maximize work and parallelism. This research uses DHT11 sensor as an indicator of temperature and humidity detection.

\subsection{Arduino integrated development environment (IDE)}

Arduino is defined as an open-source electronic platform, based on software and hardware that is flexible and easy to use, aimed at artists, designers, hobbies and anyone who is interested in creating interactive objects or environments. Arduino as a physical computing platform (physical computing) which is open source on a simple output board input, what is meant by a physical computing platform here is a 
physical system interactive with the use of software and hardware that can detect and respond to situations and conditions [13]-[25]. To program the Arduino board, the built-in integrated development environment (IDE) application from Arduino is needed. The IDE is short for Integrated development environment, or in simple language is an integrated environment that is used to carry out development. This application is useful for creating, opening, and editing Arduino source code. Furthermore, if we mention the source code written for Arduino, then we will also call sketch. Sketch is a source code that contains logic and algorithms that will be uploaded into the microcontroller IC [13]-[25].

\section{RESULTS AND DISCUSSION}

\subsection{System description}

Prototype of the temperature control system and humidity of the broiler chicken house based on the ATMega328 microcontroller is a design of temperature and humidity control devices that are automatically useful to create the ideal temperature and humidity environment for poultry broilers so as not to over heating the livestock. The use of this tool will run automatically based on commands or source code that is embedded into the microcontroller. In conditions where the temperature increases, the DHT11 sensor will detect the temperature as well as the humidity that will be displayed on the liquid crystal display (LCD) 16x2 and instruct the water pump to turn on and splash water in the form of water dew through a relay that is set based on the soucecode on the Arduino ATMega328, this tool is also equipped with buzzer output that is useful as a sign or warning will change to a higher temperature. Using this tool can help streamline the time and energy of farmers, especially Broilers with open cage [6], [13]-[25].

\subsection{Tool design}

The making of the prototype of this temperature and humidity regulation system goes through several manufacturing stages. Starting with preparing the tools and materials to be used such, as acrylic box and Arduino mainboard arrangement. The purpose of making acrylic box is intended as a container to put electronic components in order to facilitate and adjust the system in its use. In the next process is to make an electronic schematic series of temperature and humidity control systems where the Arduino ATMega328 microcontroller is connected several other components such as the DHT11 sensor, 2 channel relay, buzzer, light-emitting diodes (LED) indicator, 16x2 LCD, batrai, water pump and several other components.

\subsection{Constructing}

At the stage of making this circuit what is done is to prepare the components to be used such as, the DHT11 sensor, Arduino Uno ATMega328. In Arduino Uno there is already an ATMega328 Microcontroller, which has 14 digital input/output pins (6 Outputs for pulse width modulation (PWM)), the Arduino circuit is also equipped with a regulator IC that functions as a power supply circuit. This series was added with the presence of a buzzer as an alarm, LCD 16x2 as a display of temperature values and LEDs that function as a form of notification in the form of flashing lights on the circuit. For DHT11 sensor circuits use a $10 \mathrm{k}$ resistor, and get a 5 volt electrical input to deliver impaction to the Arduino, whereas for LEDs and water pumps are connected to the relay circuit. Can be seen in Figure 3.

\subsection{Flowchart}

Flowchart is a showing chart a flow or flow in a program or logical procedures, where flowcharts are much needed in order to simplify the way to understand a system flow that will be built [26]. The system will work when the DHT11 sensor detects the temperature and humidity of the enclosure environment, based on the predetermined temperature value set on the microcontroller. If the temperature value is above $29^{\circ} \mathrm{C}$ then the water pump will turn on as well as the water pump will turn off automatically when the temperature is below $30{ }^{\circ} \mathrm{C}$. The working principle of the temperature and humidity control system is that if the sensor detects a high temperature whose value has been determined then the LED lights will flash red; the buzzer will turn on the relay to work to turn on the water pump. Can be seen in Figure 4.

\subsection{Programs}

The program used in the control system this temperature and humidity using the application Arduino IDE. Arduino IDE is short from integrated development environment. An integrated environment that is used to perform this software development is the arduino programming that performs functions which are implanted through syntax programming. It can be seen in Figure 5. 


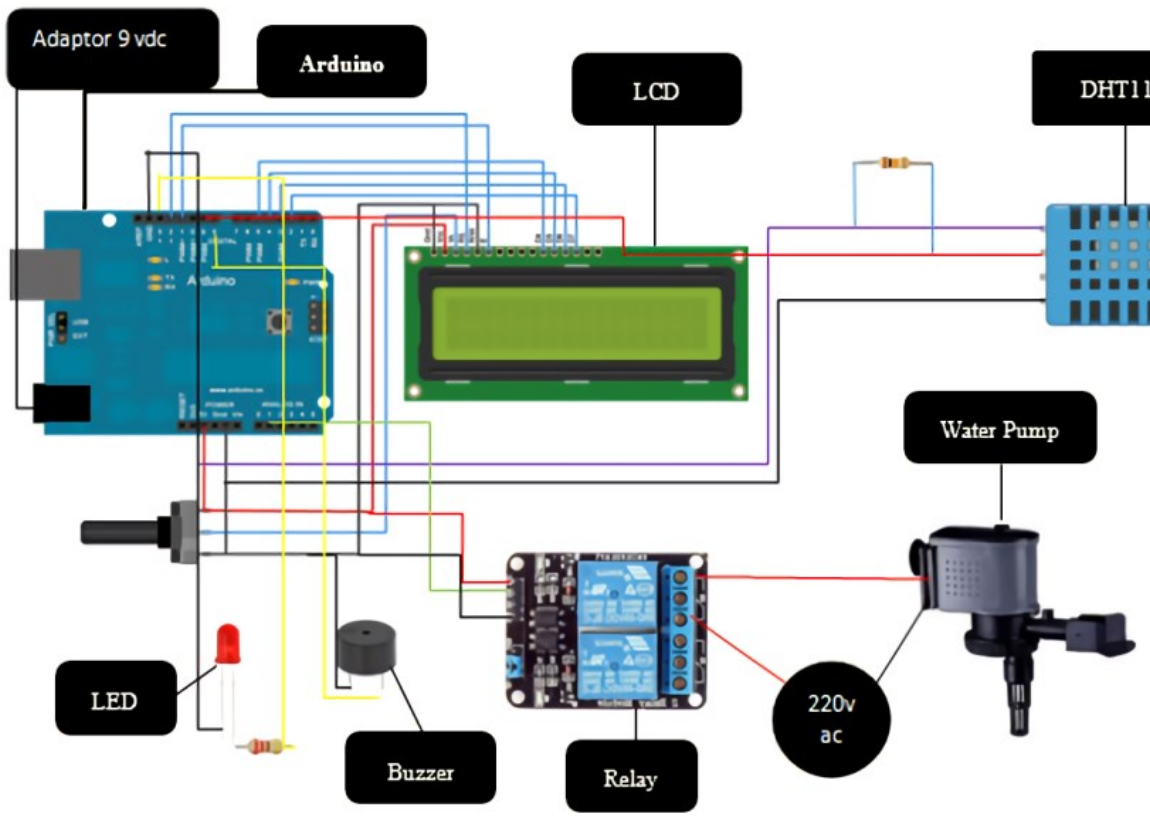

Figure 3. Component installation series

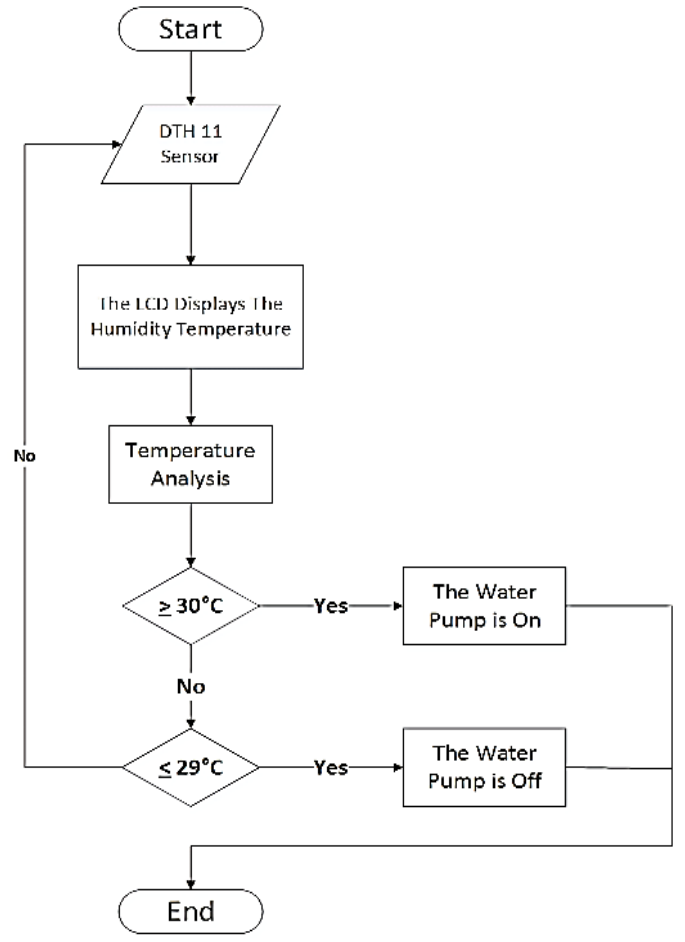

Figure 4. System flowchart

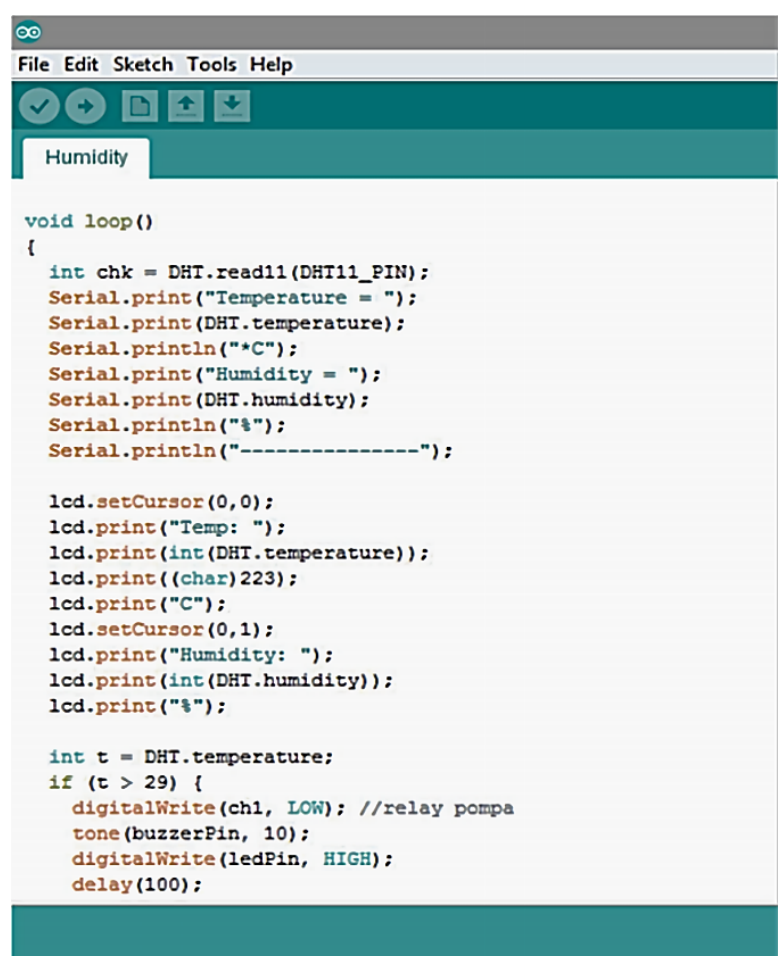

Figure 5. Arduino IDE program

\subsection{Implemetation}

Figure 6 is a physical display of output components such as LCDs and water pumps, LCDs are used to display the temperature and humidity values that are in the environment, in the temperature and humidity control system, this water pump is used as a medium to flush dew water. Implementation is the stage where all commands that have been made are entered into the Arduino Uno ATMega328. Figure 7 shows the process of entering commands from the Arduino IDE program into the Arduino Uno ATMega328 board. The upload process does not require a long time just by connecting the microcontoler to the computer 
using a universal serial bus (USB) cable, opening the Arduino IDE program, then preparing the commands or source code that will be uploaded, then uploading the source code by selecting the upload button.

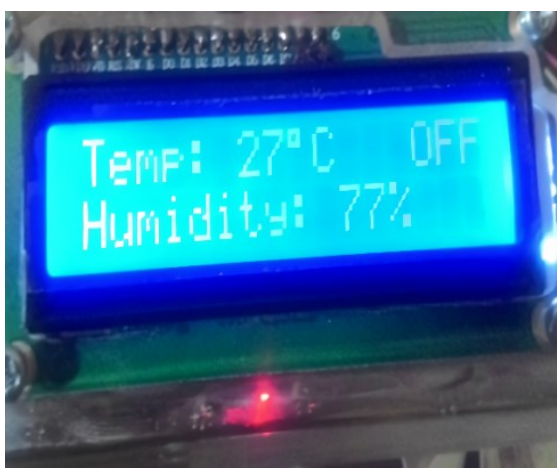

Figure 6. Output LCD



Figure 7. Process upload arduino program innovations deserving exploratory analysis (IDEA)

\subsection{System testing}

The last stage in this research is testing the system on the device, where all components are connected well, and has been ordered inside microcontroller. The testing of the system circuit of this tool was carried out using matches as a source of heat generation, which would be detected by the DHT11 sensor [6], [14], [17]. On the market there are two types of DHT11 types that are generally already in the form of modules, namely DHT11 with 3 pins and 4 pins. How to identify the pin, face the sensor facing us, the leftmost pin is the first pin [23]-[25]. Figure 8 is a physical display of the DHT11 sensor used in the temperature and humidity control system, the DHT11 sensor has the advantage to detect temperature; the DHT11 sensor can also detect humidity as shown in Figure 8. If the temperature value is above $29{ }^{\circ} \mathrm{C}$ then the water pump will turn on as well as the water pump will turn off automatically when the temperature is below $30^{\circ} \mathrm{C}$.
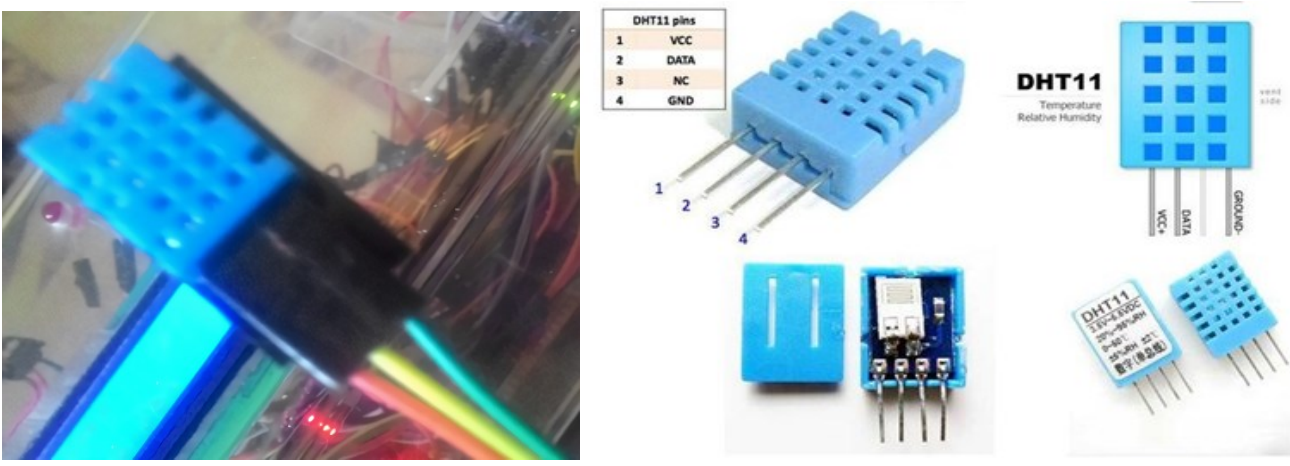

Figure 8. DHT11 sensor

\section{CONCLUSION}

Based on the results of the study and description of the series of systems, it has run according to research planning. Starting from the preparation of tools, design and manufacture of the system, to testing, it can be concluded that the temperature and humidity control system can work well. All important components such as DHT11 sensor, LCD, LED buzzer and water pump can function properly. The DHT11 sensor detects temperature and humidity in an open chicken coop area. This control system will work automatically and repeatedly when the DHT11 sensor detects high temperature levels in the chicken coop. Based on the results of this study, there are some suggestions that are very useful for this stage further development. Among others are; provide a monitor that will later be useful for monitoring temperature and humidity that occur. Second, it provides additional Android applications for facilitate monitoring via smartphone. Third, adding solar panels to provide electricity that is continuous and efficient. Fourth, do the installation of a series of components, such as the Board and cables that are more orderly and neater so eases the component release 
process on acrylic box. Finally, add a light bulb to keep the temperature warm when there is a drop in temperature very low.

\section{REFERENCES}

[1] Lara L. J. and Rostagno M. H., "Impact of Heat Stress on Poultry Production," Animals, vol. 3, no. 2, pp. 356-369, 2013, doi: 10.3390/ani3020356.

[2] M. Czharick et al., "Poultry Housing for Hot Climates," Second Edition, Cromwell Press, Trowbridge. UK. CABI Publishing, pp. 80-130, 2008.

[3] Defra, "Heat stress in poultry: solving the problem," Department of environment, food and rural affairs. Defra Publications, pp. 1-28, 2005.

[4] D. Renaudeau et al., "Adaptation to hot climate and strategies to alleviate heat stress in livestock production," in, Special Issue 5 (Symposium "Sustainable animal production in the tropics" (SAPT), Guadeloupe, France, Cambridge University Press, vol. 6, no. 5, pp. 707-728, 2012, doi: 10.1017/S1751731111002448.

[5] A. Nardone et al., "Effects of climate changes on animal production and sustainability of livestock systems," in Livestock Science, vol. 130, no. 1-3, pp. 57-69, 2010, doi: 10.1016/j.livsci.2010.02.011.

[6] O. M. Olaniyan et al., "Design and Implementation of a Temperature and Humidity Control System for a Poultry House Prototype ATBU," Journal of Science, Technology \& Education (JOSTE), vol. 6, no.1, pp. 106-114, 2018.

[7] M. K. Padhi, "Importance of Indigenous Breeds of Chicken for Rural Economy and Their Improvements for Higher Production Performance," Hindawi Publishing Corporation Scientifica, vol. 2016, pp. 1-9, 2016, doi: $10.1155 / 2016 / 2604685$.

[8] Alimuddin et al., "Temperature Control System in Closed House for Broilers Based on ANFIS," TELKOMNIKA Telecommunication Computing Electronics and. Control, vol. 10, no. 1, pp. 75-82, 2012, doi:10.11591/telkomnika.v10i1.656.

[9] M. Shubham, et al., "IOT Based Smart Poultry Farm," International Research Journal of Engineering and Technology (IRJET), vol. 6, no. 3, pp. 2380-2384, 2019

[10] P. Prima et al., "Monitoring System Design System as Measuring Temperature Measures," International Conference Sustainable Development Goals 2030 Challenges and Its Solutions 11-12 August, vol. 1, no. 1, pp. 446-457, 2017.

[11] E. H. von Borell, "The biology of stress and its application to livestock housing and transportation assessment," American Society of Animal Science, pp. E260-E267, 2001.

[12] M. H. Ca, W. Q. Lai, and L. X. Xiao, "Effect of Brooding in Cage or on Ground on Growth Performance of Chickens," China Poultry, vol. 19, no. 33, pp. 23-27, 2011.

[13] Rajesh Shrestha, "Study and Control of DHT11 Using Atmega328P Microcontroller," International Journal of Scientific \& Engineering Research, vol.10, no. 4, pp. 518-521, 2019.

[14] G. Naveen Balaji et al., "IoT Based Smart Crop Monitoring in Farm Land," Imperial Journal of Interdisciplinary Research (IJIR), vol. 4, no.1, pp. 88-92, 2018.

[15] D.O.Shirsath, "IOT Based Smart Greenhouse Automation Using Arduino," International Journal of Innovative Research in Computer Science \& Technology (IJIRCST), vol. 5, no. 2, 2017, doi: 10.21276/ijircst.2017.5.2.4.

[16] Akash, \& Birwal, A., "IoT-based Temperature and Humidity Monitoring System for Agriculture," International Journal of Innovative Research in Science, vol. 6, no. 7, pp. 12756-12761, 2017.

[17] Aravinth Raj S, V. Venkatesh, "Implementation of Wireless Sensor Network with Low Cost and Low Power using Arduino and nRF24L0," International Journal of Pure and Applied Mathematics, vol. 119, no. 18, pp. 2095-2103, 2018.

[18] A. N. Arvindan and D. Keerthika, "Experimental investigation of remote control via Android smart phone of arduino-based automated irrigation system using moisture sensor," 2016 3rd International Conference on Electrical Energy Systems (ICEES), Chennai, pp. 168-175, 2016, doi: 10.1109/ICEES.2016.7510636.

[19] Y. Wang and Z. Chi, "System of Wireless Temperature and Humidity Monitoring Based on Arduino Uno Platform," Sixth International Conference on Instrumentation \& Measurement, Computer, Communication and Control (IMCCC) Harbin, China: IEEE. pp. 770-773, 2016, doi: 10.1109/IMCCC.2016.89.

[20] P. S. N. Reddy, K. T. K. Reddy, P. A. K. Reddy, G. N. K. Ramaiah, and S. N. Kishor, "An IoT based home automation using android application," 2016 International Conference on Signal Processing, Communication, Power and Embedded System (SCOPES), Paralakhemundi, pp. 285-290, 2016, doi: 10.1109/SCOPES.2016.7955836.

[21] T. S. Gunawan et al., "Prototype Design of Smart Home System using Internet of Things," Indonesian Journal of Electrical Engineering and Computer Science (IJEECS), vol. 7, no. 1, pp. 107-115, 2017, doi: 10.11591/ijeecs.v7.i1.pp107-115.

[22] Z. A. Jabbar, R. S. Kawitkar, "Implementation of Smart Home Control by Using Low Cost Arduino \& Android Design," International Journal of Advanced Research in Computer and Communication Engineering, vol. 5, no. 2, pp. 248-256, 2016, doi: 10.17148/IJARCCE.2016.5250.

[23] Nor Sehah Abd Karim et al., "Urbanized Chicken Coop Monitoring System using IoT," International Journal of Advanced Trends in Computer Science and Engineering, vol. 8, no. 1.6, pp. 450-454, 2019, doi: $10.30534 /$ ijatcse/2019/6581.62019.

[24] M. A. E. L. Mowad, et al., "Smart Home Automated Control System Using Android Application and Microcontroller," International Journal of Scientific \& Engineering Research, vol. 5, no. 5, pp. 935-939, 2014.

[25] Kornuta et.al, "Low-cost microcontroller platform for studying lymphatic biomechanics in vitro," Journal of biomechanics, vol. 46, no. 1, pp. 183-186, 2013, doi: 10.1016/j.jbiomech.2012.09.031.

[26] Ramadianiet et al., "Decision support system for determining chili land using weighted product method," Bulletin of Electrical Engineering and Informatics, vol. 9, no. 3, pp. 1229-1237, 2020, doi: 10.11591/eei.v9i3.2004. 


\section{BIOGRAPHIES OF AUTHORS}
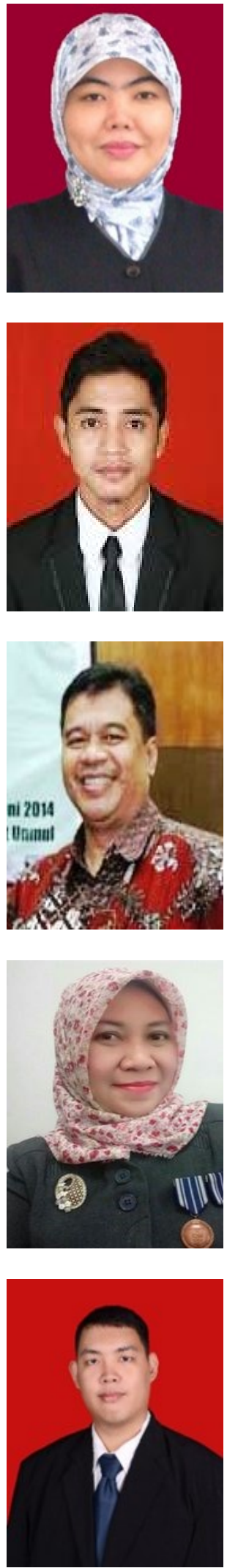

Ramadiani obtained her Ph.D in Information System from Univesiti Putra Malaysia (UPM) in 2015. She received her first degree from Mulawarman University (1996), her M.Kom. in Computer Science from Gadjah Mada University (2006). Ramadiani currently works at the Department of Computer Science, Universitas Mulawarman. Ramadiani does research in Software Engineering, system control, expert system, Information Systems, Human-computer interaction, e-Learning and Decision Support System.

Eko Wiji Setio Budianto, born on February 14, 1994 in Tarakan City, North Kalimantan Kilian majored in Computer Science, Faculty of Computer Science and Information Technology in 2013 and graduated from college in 2017.

Dharma Widada graduated with a Bachelor of Industrial Engineering from the Bandung Institute of Technology (1999) and obtained a Masters of Engineering from the Bandung Institute of Technology (2002). He completed his Doctorate in forestry at Mulawarman University in 2012. He has been a do engineering lecturer at Mulawarman University since 2002. His research areas include decision analysis, production process and management, supply chain management, and electrical energy conversion.

Masayu Widiastuti graduated with Bachelor of Geotechnical Engineering from the Malang Institute of Technology (1988-1993) and obtained her Master of Geotechnical Engineering from Gadjah Mada University (2003-2005). She has been a lecturer in engineering at Mulawarman University since 2002. Her field of research is the quality of soil, water, metal and non-metal materials for environmental improvement.

Muhammad Labib Jundillah S.Kom, M.Kom received his M.Kom degree in Information System (2019) from Diponegoro University Semarang Indonesia. He obtained his S.Kom from Mulawarman University (2017) Samarinda. His research interests area in Information System, Decision Support System, Software Engineering and User Statisfication. 